\title{
Mitigation of Distributed Generation Impact on Protective Devices in a Distribution Network by Superconducting Fault Current Limiter ${ }^{*}$
}

\author{
Yu Zhao ${ }^{1}$, Yong Li $^{2}$, Tapan Kumar Saha ${ }^{1}$, Olav Krause ${ }^{1}$ \\ ${ }^{1}$ School of Information Technology and Electrical Engineering, University of Queensland, Australia \\ ${ }^{2}$ College of Electrical and Information Engineering, Hunan University, Changsha, China \\ Email: y.zhao5@uq.edu.au,yongli@hnu.edu.cn,o.krause@uq.edu.au, saha@itee.uq.edu.au
}

Received April, 2013

\begin{abstract}
Protection of radial distribution networks is widely based on coordinated inverse time overcurrent relays (OCRs) ensuring both effectiveness and selectivity. However, the integration of distributed generation (DG) into an existing distribution network not only inevitably increases fault current levels to levels that may exceed the OCR ratings, but it may also disturb the original overcurrent relay coordination adversely effecting protection selectivity. To analyze the potentially adverse impact of DG on distribution system protective devices with respect to circuit breaker ratings and OCR coordination fault current studies are carried out for common reference test system under the influence of additional DG. The possible advantages of Superconducting Fault Current Limiter (SFCL) as a means to limit the adverse effect of DG on distribution system protection and their effectiveness will be demonstrated. Furthermore, minimum SFCL impedances required to avoid miss-operation of the primary and back-up OCRs are determined. The theoretical analysis will be validated using the IEEE 13-bus distribution test system is used. Both theoretical and simulation results indicate that the proposed application of SFCL is a viable option to effectively mitigate the DG impact on protective devices, thus enhancing the reliability of distribution network interfaced with DG.
\end{abstract}

Keywords: Overcurrent Relay (OCR); Distribution Protection Coordination; Distributed Generation (DG); Fault Current; Superconducting Fault Current Limiter (SFCL)

\section{Introduction}

In recent years, mainly due to environmental concerns and in preparation for an expected shortage of traditional fossil fuel based energy, distributed generation (DG) based on renewable energy sources is attracting more and more attention. The advantages of introducing DG into a distribution system are generally called "system support benefits" such as voltage support, improved power quality, loss reduction as well as transmission and distribution capacity release [1]. However, there are several disadvantages introduced by DG. For instance, the increasing fault current levels may exceed the current ratings of circuit breakers (CBs), which lead to the need for expensive upgrading of CBs [2]. Another impact of DG is the disturbance on existing protection coordination. Since distribution systems are for the predominant part of radial structure, the inverse time Overcurrent Relays (OCRs) [3] are the most applied protection device in dis-

\footnotetext{
${ }^{*}$ This paper was partly supported by the national Nature Science
} Foundation of China (NSFC) under Grant 51007020. tribution systems. However, when DGs are installed in a distribution system, the typical one-direction nature of power flow can be lost. In such case, there is a risk of existing relay coordination to be disturbed or even becoming ineffective [4].

Several possible solutions have been proposed to overcome the above problems, such as upgrading circuit breakers, installing microprocessor based recluses [5], employing adaptive protection [6], decreasing the generation capacity of DGs or even cut off the DGs from the main grid during fault conditions [7]. These methods are complex and expensive, and in many cases put constraint in using DG capacity and limiting the benefits from DG units.

As will be shown in this paper, Superconducting Fault Current Limiter (SFCL) can be used to minimize the adverse impact of DGs on distribution system protection. SFCL represents a near-zero impedance during normal operating conditions, thus causing a negligible voltage drop and power loss. However, during fault condition, it introduces high serial impedance limiting the short- cir- 
cuit current flowing though the SFCL. Therefore SFCL in series with DG units are able to decrease the adverse impacts of DG to the distribution system protection during network faults.

This ability as well as the minimum SFCL impedance requirements during fault conditions is analyzed in this paper, which is organized as follows. Section 2 analyses the effect of DG on the protection coordination of distribution systems. In Section 3, the functioning principle of SFCL is analyzed and its mathematical model is established. In Section 4, a case study is used to investigate the impact of SFCL on protection of distribution systems with DG with respect to CB fault current levels and coordination of OCRs. Finally, the conclusions are given in Section 5.

\section{Impact of DG on Overcurrent Relay (OCR) Coordination}

\subsection{Principle of OCR}

The protective devices in a power system are used to operate CBs correctly to detect and clear faults with minimum customer interruption and as quickly as possible. Inverse time OCRs are most commonly used in a radial distribution system. The operating time of OCRs is inversely proportional to the current flow $I$ through the relay exceeding the pick-up current threshold $I_{\text {pick-up. The }}$ tripping time $t_{\text {trip }}(I)$ is given by the following equation, where TDS is the time-dial setting, which adjusts the time-delay curve between minimum and maximum curves for the particular relay. Here $A, B, p$ and $K$ are constants that represent different types of OCR:

$$
\left\{\begin{array}{l}
t_{\text {trip }}(I)=T D S \times\left(\frac{A}{M^{p}-1}+B\right)+K \\
M=I / I_{\text {pick-up }}
\end{array}\right.
$$

Results presented in this paper were obtained using $A=3.922, B=0.0982, p=2$ and $K=0$ based on the "very inverse type OCR" defined by IEEE Std. C37. 112-1996 [8]. For this study TDS values are taken from an interval between 0.5 and 11 s, which are used to tune response times at same current levels.

For systems with multiple installed OCRs, relays installed in series should be coordinated to ensure relay response in a specified operation sequence, that is to say, primary relay near the fault location is supposed to trip first, and the back-up relay is supposed to trip only in case of a primary relay fails. This is to ensure maximum selectivity and to limit the number of customers affected by the required de-energization of sections of the network. Therefore, the Coordinated Time Interval CTI, specifying the time between the primary relay's tripping time $t_{\text {trip,primary }}$ and the back-up relay's tripping time $t_{\text {trip,back-up }}$ is defined as follows:

$$
C T I \leq t_{\text {trip,back }}-t_{\text {trip, primary }}
$$

Typical CTI values range between $0.2 \mathrm{~s}$ and $0.5 \mathrm{~s}$. For the results presented in this paper CTI values are set to around $0.25 \mathrm{~s}$. Value for $I_{\text {pick-up }}$ and TDS are chosen according to the magnitude of load and fault current flowing through each OCR and the required operating times to clear the corresponding fault. The selection of these two values should satisfy the following conditions:

- The primary relay must trip over the level of $1 / 3$ of minimum fault current of the back-up relay;

- The CTI between primary and back-up relays are set around $0.25 \mathrm{~s}$ and must be over $0.2 \mathrm{~s}$ to avoid miss-tripping.

\subsection{Analysis of DG Impact}

When DGs are integrated into a distribution system, the Thévenin impedance seen from a possible fault location will decrease and thus the corresponding fault current level will increase, which may exceed the interrupting capacity of the installed CBs. For example, when a fault $F_{1}$ occurs in Figure 1, the fault current flowing through $\mathrm{CB}_{2}\left(I_{\mathrm{CB}_{2}}\right)$ is calculated as:

$$
I_{C B_{2}}=I_{s}+I_{D G}
$$

where, $I_{s}$ is the fault current flowing through $\mathrm{CB}_{2}$ from the source feeder before the presence of DG, then the resulting $I_{C_{2}}$ will be greater than $I_{s}$ with help of $I_{D G}$ supplied by DG. Therefore, in some cases the fault current $I_{\mathrm{CB}_{2}}$ in the system with DG may exceed the rated current of the specific $\mathrm{CB}$, which is selected in accordance with $I_{s}$.

Additionally, the application of DG in a distribution network may cause wrong relay coordination. For instance, the OCRs $R_{1}, R_{2}$ and $R_{3}$ in Figure 1 have been coordinated properly for a fault at $F_{1}$ and $F_{2}$. The operating time of $\mathrm{R}_{2}$ is larger than that of $\mathrm{R}_{3}$ by a certain CTI value while the operating sequence for relay $R_{1}$ and $R_{2}$ is similar. However, when DG is connected, the coordination between these two pairs of relays $\left(R_{1}-R_{2}\right.$ and $\left.R_{2}-R_{3}\right)$ is likely to be disturbed by the decreasing operation time of $R_{2}$ and $R_{3}$, which is determined by the increasing fault current flowing through them. Therefore, the CTI between $\mathrm{R}_{2}$ and $\mathrm{R}_{3}$ may decrease and CTI between $\mathrm{R}_{1}$ and $\mathrm{R}_{2}$ may increase.

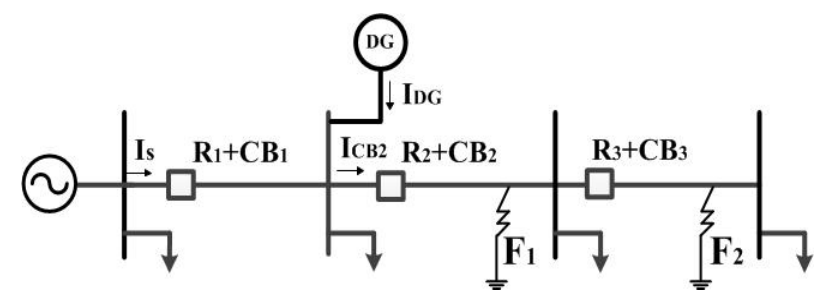

Figure 1. DG impact analysis. 


\section{Application of SFCL}

A Fault Current Limiter (FCL) is a device for detecting, triggering and limiting fault currents in power systems. An ideal FCL works in low impedance at standby state thus causes little contribution to power loss of a healthy system. However, it rapidly converts to a high impedance when a fault occurs, decreasing the fault current. Among all types of FCL, the usefulness and usability of Superconducting Fault Current Limiters (SFCLs) are widely investigated due to the advantage of inherent self-triggering, fast response and self-recovery. The quenching and recovery characteristics of a resistive type SFCL can be described as follows:

$$
R_{S F C L}(t)= \begin{cases}0 & t<t_{f} \\ R_{n}\left[1-\exp \left(1-\frac{t-t_{f}}{T_{F}}\right)\right]^{\frac{1}{2}} & t_{f}<t<t_{r} \\ a\left(t-t_{r}\right)+b & t>t_{r}\end{cases}
$$

In Equation $4 R_{n}$ refers to the maximum resistance of the specific SFCL, $T_{F}$ refers to the time constant of transition from the superconducting state to the non-superconducting state, while $t_{f}$ and $t_{r}$ are the time intervals for SFCL starting quenching and starting recovery respectively. Variables $a$ and $b$ are constants related to recovery characteristic.

The impact of the SFCL on a connected DG unit during fault conditions is determined by its current limiting performance on the DG current. A model of DG-SFCL unit has been developed in the environment of PSCAD/EMTDC [9], based on the mathematical model defined by Equation 4. To illustrate the SFCL performance Figure 2 depicts the DG fault current contribution $I_{a}$ resulting from a simulated fault in the network, with $I_{a 0}$ depicting the non-limited DG fault current contribution as a reference. Here, the quenched impedance of SFCL is selected equals to the line impedance of the small system.

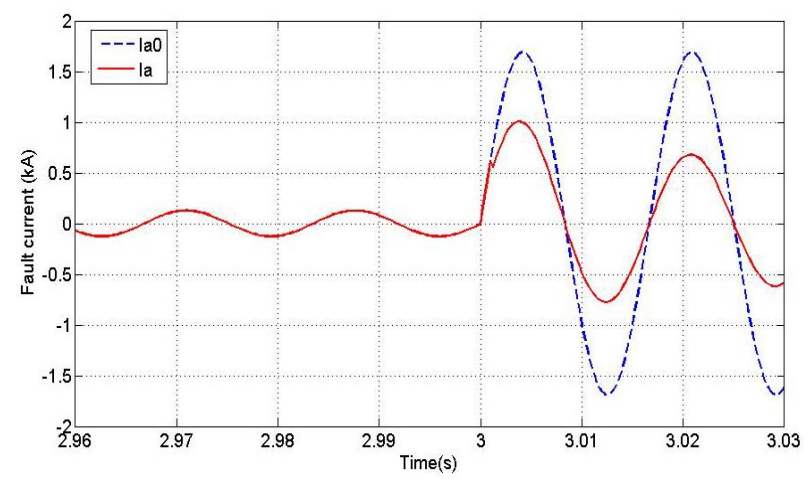

Figure 2. DG fault current limitation by a SFCL.
As can be seen in Figure 2, the peak value of fault current $I_{a 0}$ before the installation of a SFCL (approximately $1.8 \mathrm{kA}$ ) is more than 10 times of the normal operation current (the magnitude is around $150 \mathrm{~A}$ ). By installing a SFCL in series to the DG, this fault current peak can be limited by around 50\% (being reduced to about $1 \mathrm{kA}$ ) of its non-limited value. Note that the current limiting performance greatly depends on the non-superconducting impedance of SFCL, which will be discussed later on.

\section{Case study}

\subsection{IEEE 13-bus Distribution Network}

The test network used in this study is $4.16 \mathrm{kV}$ IEEE 13-bus distribution network, which is a radial unbalanced power system with three-phase, two-phase and single-phase lines as well as unbalanced wye load and delta load [10]. Figure 3 shows the single-line diagram of 13-bus system protected by 10 protection units (OCRs and CBs).

The system configuration, line impedance and load data with no DG are given by IEEE PES Distribution Systems Analysis Subcommittee [10]. The first step of the study carried out for this paper was to calculate the load and fault currents, in purpose of determining the operating times and required CTI between each pair of OCRs based on the two conditions described in Section 2. The second step consisted of introducing an additional three-phase load $S=(600+j 30) \mathrm{kVA}$ at bus 680 and an additional $660 \mathrm{kVA}$ wind turbine at bus 675 to supply the increasing power. This changes the power and current flows, leading to fault current increasing and disturbance of the protective coordination between some pairs of relays during fault conditions. As the final step, a model of SFCL is developed and added to the DG connection.

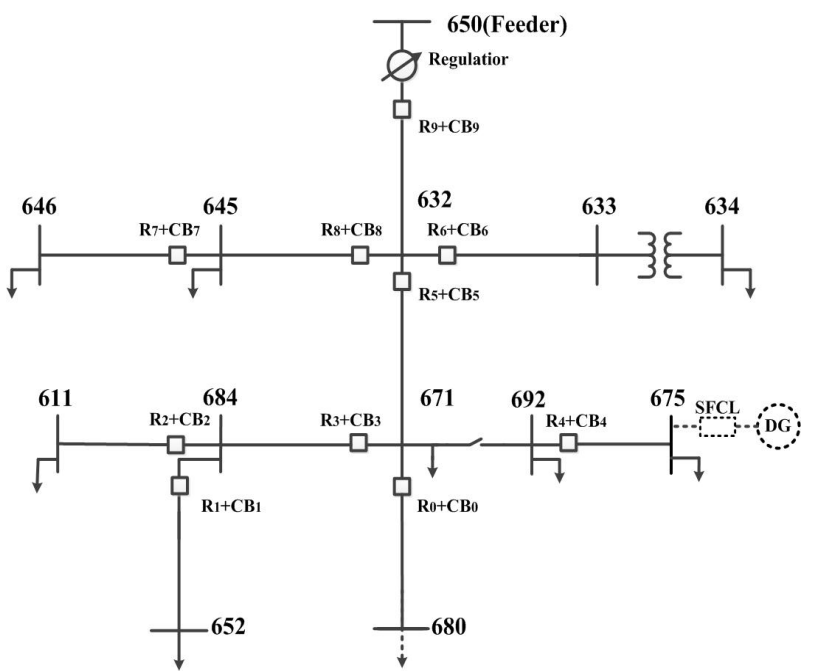

Figure 3. IEEE 13-bus distribution network [10]. 
The purpose is to investigate its performance during faults by minimizing the DG's adverse impact on protection coordination.

\subsection{DG and SFCL Impact on CB Fault Currents}

The required rated current level of CB is determined by the highest fault current that might have to be cleared by it. In this section, some simulations are carried out to analyze the impact of DG and SFCL to the fault current, when faults occur at the terminal of each CB. Table 1 shows the highest RMS value of the fault currents flowing through CB1, CB2, CB3, CB7 and CB8, for the proposed distribution network without DG, with DG and with DG-SFCL unit.

As shown in Table 1, SFCL can decrease the fault current effectively for all CBs while comparing without a use of SFCL. As the SFCL is installed in series with DG unit, it is used to limit the DG current contribution to the main grid during a fault. Its current limiting performance turns out to be better for those CBs that located closer to it. This can also be observed in Table 1 that the current limiting performance is more significant for nearby $\mathrm{CBs}$ $\left(\mathrm{CB}_{1}, \mathrm{CB}_{2}\right.$ and $\left.\mathrm{CB}_{3}\right)$. Moreover, the limiting performance is highly affected by the parameter of SFCL $\left(R_{S F C L}\right)$. Figure 4 shows the relationship between fault current (RMS) and SFCL resistivity $\left(R_{S F C L}\right)$. It can be observed that the fault current limiting performance becomes better with increasing resistivity of the SFCL.

\subsection{DG and SFCL Impact on OCR Coordination}

As the load and the fault current of this 13-bus network can be calculated, the OCRs are modified in accordance with the pre-defined $I_{\text {pick-up }}$ and TDS, aiming at setting CTIs of each pair of OCRs around $0.25 \mathrm{~s}$ and in the range between $0.2 \mathrm{~s}$ and $0.5 \mathrm{~s}$. However, when a DG is connected into the network, the protection coordination will be disturbed. In purpose of investigating the changes, a number of simulations in PSCAD/EMTDC environment have been carried out. The results of three-phase and single line to ground faults at the terminal of different buses before and after the introduction of DG are shown in Tables $\mathbf{2}$ and $\mathbf{3}$ respectively. For a fault occurrence at

Table 1. Fault current of each CB (kA).

\begin{tabular}{cccccc}
\hline \multirow{2}{*}{$\mathrm{CB}$} & \multirow{2}{*}{ No DG } & \multicolumn{2}{c}{ with DG } & \multicolumn{2}{c}{ with DG and SFCL( $\left.\mathrm{R}_{\mathrm{SFCL}}=2 \mathrm{pu}\right)$} \\
\cline { 3 - 6 } & & Current & increase rate & Current & increase rate \\
\hline $\mathrm{CB}_{1}$ & 2.34 & 2.71 & $15.8 \%$ & 2.48 & $6.0 \%$ \\
$\mathrm{CB}_{2}$ & 2.32 & 2.65 & $14.2 \%$ & 2.48 & $6.9 \%$ \\
$\mathrm{CB}_{3}$ & 2.68 & 3.17 & $18.3 \%$ & 2.90 & $8.2 \%$ \\
$\mathrm{CB}_{7}$ & 3.61 & 3.80 & $5.3 \%$ & 3.71 & $2.8 \%$ \\
$\mathrm{CB}_{8}$ & 4.30 & 4.58 & $6.5 \%$ & 4.44 & $3.2 \%$ \\
\hline
\end{tabular}

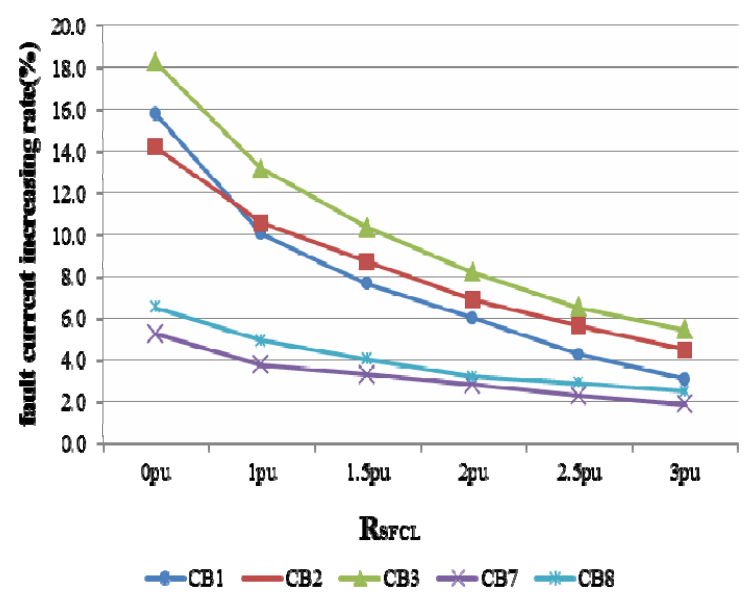

Figure 4. Fault current limiting effect of SFCL.

Table 2. Setting value of each OCR (three-phase faults).

\begin{tabular}{|c|c|c|c|c|c|}
\hline \multirow{2}{*}{$\begin{array}{c}\text { Fault } \\
\text { Location }\end{array}$} & \multirow{2}{*}{$\begin{array}{c}\text { Relay } \\
\text { No. }\end{array}$} & \multicolumn{2}{|c|}{ Without DG } & \multicolumn{2}{|c|}{ With DG } \\
\hline & & Trip time(s) & CTI(s) & Trip time(s) & CTI(s) \\
\hline \multirow{2}{*}{680} & $\mathrm{R}_{0}$ & 0.160 & & 0.155 & \\
\hline & $\mathrm{R}_{5}$ & 0.385 & 0.225 & 0.385 & 0.230 \\
\hline \multirow{2}{*}{675} & $\mathrm{R}_{4}$ & 0.109 & & 0.109 & \\
\hline & $\mathrm{R}_{5}$ & 0.337 & 0.228 & 0.337 & 0.228 \\
\hline \multirow{2}{*}{692} & $\mathrm{R}_{5}$ & 0.285 & & 0.285 & \\
\hline & $\mathrm{R}_{9}$ & 0.568 & 0.283 & 0.568 & 0.283 \\
\hline \multirow{2}{*}{633} & $\mathrm{R}_{6}$ & 0.129 & & 0.129 & \\
\hline & $\mathrm{R}_{9}$ & 0.342 & 0.213 & 0.342 & 0.213 \\
\hline
\end{tabular}

Table 3. Setting value of each OCR (single-phase faults).

\begin{tabular}{|c|c|c|c|c|c|}
\hline \multirow{2}{*}{$\begin{array}{c}\text { Fault } \\
\text { Location }\end{array}$} & \multirow{2}{*}{$\begin{array}{c}\text { Relay } \\
\text { No. }\end{array}$} & \multicolumn{2}{|c|}{ Without DG } & \multicolumn{2}{|c|}{ With DG } \\
\hline & & Trip time(s) & CTI(s) & Trip time(s) & CTI(s) \\
\hline \multirow{2}{*}{$\begin{array}{c}652 \\
(\mathrm{~A}-\mathrm{G})\end{array}$} & $\mathrm{R}_{1}$ & 0.555 & & 0.400 & \\
\hline & $\mathrm{R}_{3}$ & 0.793 & 0.238 & 0.581 & 0.181 \\
\hline \multirow{2}{*}{$\begin{array}{c}684 \\
(\mathrm{~A}-\mathrm{G})\end{array}$} & $\mathrm{R}_{3}$ & 0.606 & & 0.430 & \\
\hline & $\mathrm{R}_{5}$ & 0.831 & 0.225 & 0.735 & 0.305 \\
\hline \multirow{2}{*}{$\begin{array}{c}646 \\
(B-G)\end{array}$} & $\mathrm{R}_{7}$ & 0.620 & & 0.543 & \\
\hline & $\mathrm{R}_{8}$ & 0.838 & 0.218 & 0.743 & 0.200 \\
\hline \multirow{2}{*}{$\begin{array}{c}645 \\
(B-G)\end{array}$} & $\mathrm{R}_{8}$ & 0.601 & & 0.527 & \\
\hline & $\mathrm{R}_{9}$ & 0.873 & 0.272 & 0.832 & 0.305 \\
\hline \multirow{2}{*}{$\begin{array}{c}611 \\
(\mathrm{C}-\mathrm{G})\end{array}$} & $\mathrm{R}_{2}$ & 0.575 & & 0.421 & \\
\hline & $\mathrm{R}_{3}$ & 0.818 & 0.243 & 0.608 & 0.187 \\
\hline \multirow{2}{*}{$\begin{array}{c}684 \\
(\mathrm{C}-\mathrm{G})\end{array}$} & $\mathrm{R}_{3}$ & 0.645 & & 0.470 & \\
\hline & $\mathrm{R}_{5}$ & 0.881 & 0.236 & 0.800 & 0.330 \\
\hline \multirow{2}{*}{$\begin{array}{c}646 \\
(\mathrm{C}-\mathrm{G})\end{array}$} & $\mathrm{R}_{7}$ & 0.634 & & 0.568 & \\
\hline & $\mathrm{R}_{8}$ & 0.866 & 0.232 & 0.784 & 0.216 \\
\hline \multirow{2}{*}{$\begin{array}{c}645 \\
(\mathrm{C}-\mathrm{G})\end{array}$} & $\mathrm{R}_{8}$ & 0.612 & & 0.550 & \\
\hline & $\mathrm{R}_{9}$ & 0.845 & 0.233 & 0.828 & 0.278 \\
\hline
\end{tabular}


bus $680, R_{0}$ works as the primary relay while $R_{5}$ is the back-up relay. The coordinated conditions of primary and back-up relays are similar for faults located at other buses in Tables 2 and 3.

It can be seen from Tables 2 and $\mathbf{3}$ that most of CTIs, especially for faults close to the DG are affected by the presence of DG. The values of CTIs may increase or decrease with respects to their locations and distance to the DG unit as analyzed in Section 2. In this case, the increasing CTIs are still in the range and need no adjustment. However, among those decreased CTIs, the CTI_1,3 (phase A) and CTI_2,3 (phase C) drop below $0.2 \mathrm{~s}$, which is out of the acceptable range. Therefore, the coordination of these two pairs of OCRs needs to be restored, e.g. by means of a SFCL.

Figure 5 shows the improvement of these two CTIs when a SFCL is installed, where $R_{S F C L}=2 \mathrm{pu}$. Under the presence of a SFCL, both of these two CTIs have been improved to over $0.2 \mathrm{~s}$, which satisfy the range requirement mentioned in Section 2. In addition, the contribution of SFCL to the improvement of the CTIs is more significant when the OCR pairs are located closer to the DG-SFCL unit. For instance, compared with CTI_1,3 (increasing by 0.034s), CTI_7,8 (phase C) just increases from 0.200 s to 0.209 s under the same situation.

To further investigate the relationship between different values of SFCL parameter $R_{S F C L}$ and CTIs, $R_{S F C L}$ is set to $1 \mathrm{pu}, 1.5 \mathrm{pu}, 2 \mathrm{pu}, 2.5 \mathrm{pu}$, and $3 \mathrm{pu}$. The simulation results are shown in Table 4 . It is found that the larger the SFCL resistivity, the closer is the CTIs to their previous determined setting values (see Table 3 ).

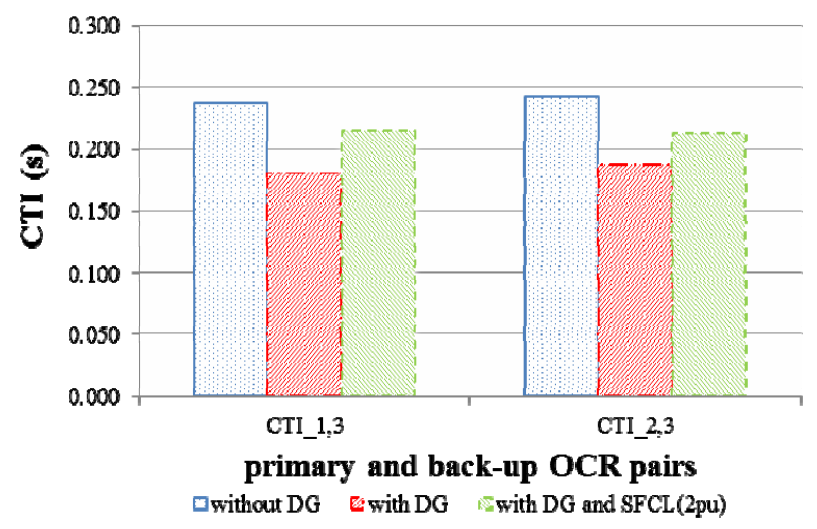

Figure 5. Comparison of CTIs.

Table 4. Comparison of CTIs with different value of RSFCL.

\begin{tabular}{ccccccc}
\hline$R_{S F C L}$ & $0 \mathrm{pu}$ & $1 \mathrm{pu}$ & $1.5 \mathrm{pu}$ & $2 \mathrm{pu}$ & $2.5 \mathrm{pu}$ & $3 \mathrm{pu}$ \\
\hline CTI_1,3 & 0.181 & 0.198 & 0.208 & 0.215 & 0.221 & 0.226 \\
CTI_2,3 & 0.187 & 0.199 & 0.206 & 0.214 & 0.219 & 0.224 \\
\hline
\end{tabular}

With the last part of this study, the minimum value of $R_{S F C L}$, which improves all CTIs to the range between $0.2 \mathrm{~s}$ and $0.5 \mathrm{~s}$ should be determined. As can be observed in Table 4, when $R_{S F C L}$ set as 1pu, CTI_1, 3 and CTI_2, 3 are slightly under $0.2 \mathrm{~s}$, while when $R_{S F C L}=1.5 \mathrm{pu}$, both of them are over $0.2 \mathrm{~s}$. Therefore, some specific tests were carried out to find the minimum value of $R_{S F C L}$ in the range between $1 \mathrm{pu}$ and $1.5 \mathrm{pu}$. The results turn out that when $R_{S F C L}$ is set to $1.1 \mathrm{pu}, C T I \_1,3$ (phase A) and CTI_2, 3 (phase C) are equal to 0.200 s and 0.201 s respectively, both of them are in the required range. At the same time, all of the increasing CTIs are under 0.5s. In other words, for this case study, a minimum value $1.1 \mathrm{pu}$ is needed for $R_{S F C L}$ to avoid any alteration of the original OCR settings.

\section{Conclusions}

The application of DG in a distribution network increases the fault current level and disturbs the protection coordination. To overcome these problems, this paper proposed a resistive type of SFCL to mitigate the adverse impact of DG to the protective devices in a radial distribution network. Simulations on the IEEE 13-bus distribution test network are carried out by using PSCAD/ EMTDC software. For this study, the issues of CB rating current levels and OCR coordination are considered. Particularly, the fault current flows through $\mathrm{CB}$ at the tripping moment is used to evaluate the current limiting performance while the CTIs between the primary and back-up OCRs operating times are used to investigate the SFCL behavior on OCR restoration. Besides, the minimum parameter of the proposed SFCL is also determined to avoid wrong coordination of all the OCR pairs. Results show that the proposed SFCL installation in series with a DG unit is able to effectively limit the fault current and at the same time improve the CTIs to its required value.

\section{REFERENCES}

[1] P. P. Barker and R. W. de Mello, "Determine the Impact of Distribution Generation on Power Systems: Part 1- radial Distribution Systems," Power Technologies, Inc., 2000.

[2] N. Hadjsaid, J. F. Canard and F. Dumas, "Dispersed Generation Impact on Distribution Networks,” IEEE Computer Application in Power, Vol. 12, 1999, pp. 22-28.doi:10.1109/67.755642

[3] C. R. Mason, "The Art and Science of Protection Relaying," General Electric Company, 1965.

[4] A. A. Girgis and S. M. Brahma, "Effect of Distributed Generation on Protective Device Coordination in Industry System", in Proceedings of Large Engineering Systems Conference on Power Engineering, 2001, pp. 115-119.

[5] S. M. Brahma and A. A. Girgis, "Microprocessor Based Reclosing to Coordinate Fuse and Recloser in a System 
with High Penetration of Distributed Generation,” in Proceedings of IEEE Power Engineering and Society, Winter Meeting, Vol. 1, 2002, pp. 453-458.

[6] S. M. Brahma and A. A. Girgis, "Development of Adaptive Protection Scheme for Distribution Systems with high Penetration of Distributed Generation,” IEEE transaction Power Delivery, Vol. 19, No. 1, 2004, pp. 56-63. doi:10.1109/TPWRD.2003.820204

[7] S. Chaitusaney and A. Yokoyama, "Impact of Protection Coordination on Sizes of Several Distributed Generation
Sources," 7th International Power Engineering Conference, Vol. 2, 2005, pp. 669-674.

[8] IEEE Standard Inverse -Time Characteristic Equations for Overcurrent Relays, 1997, IEEE Std. C37, pp. 1121996.

[9] Applications of PSCAD/EMTDC, https://hvdc.ca/pscad/

[10] IEEE PES Distribution Systems Analysis Subcommittee Radial Test Feeders,

http://ewh.ieee.org/soc/pes/dsacom/testfeeders/index.html. 